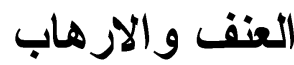

(دراسة سوسيو - انثروبولوجية في مدينة بغداد - منطقة الدورة إنموذجاً)

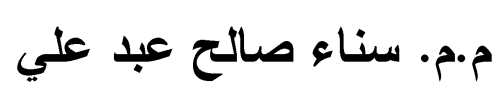

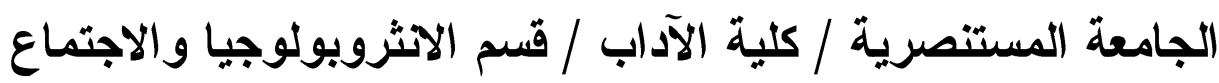

E.mail: sanaasaleh@uomustansiriyah.edu.iq

$$
\text { sanaay80@yahoo.com }
$$

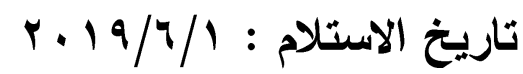

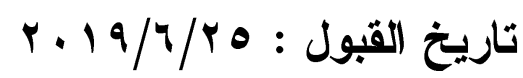

\section{(c) (i)}

This work is licensed under a Creative Commons Attribution 4.0 International License.

المُّخص : المصن

مشكلة العنف والارهاب من أكبر المشكلات التي تعاني منها المجتمعات في عالمنا المعاصر،

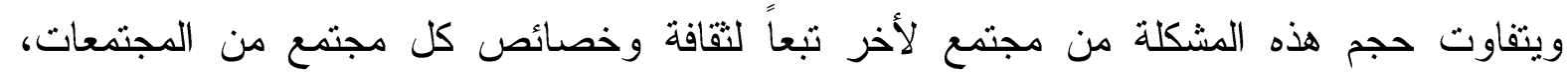
فهظاهر العنف والارهاب تعد اليوم من أبرز الظواهر الخطيرة التي تهدد الأمن الانساني للمجتمعات كافة، لذا أصبحت موضع اهتمام كبير على المستوى الدولي و العالمي.

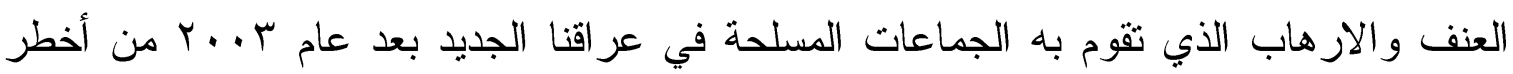

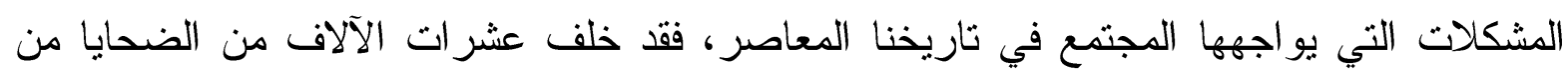

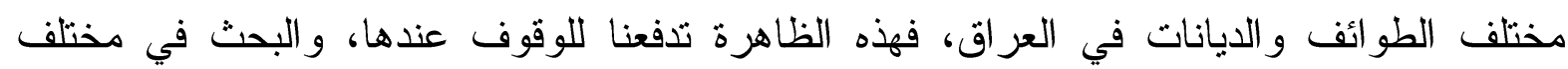

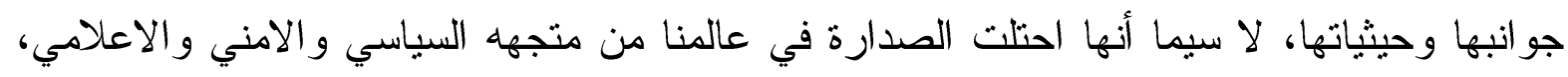

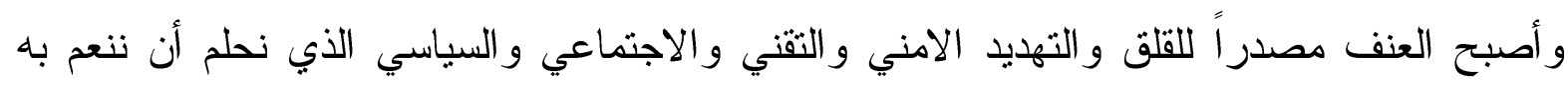
مقارنة بباقي الشعوب المستقرة أمنيا (سياسياً و إقتصادياً).

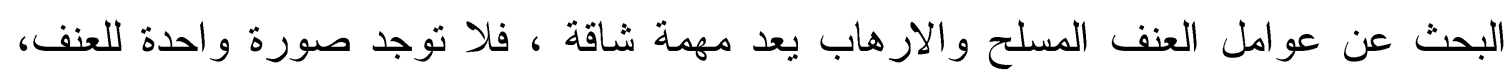

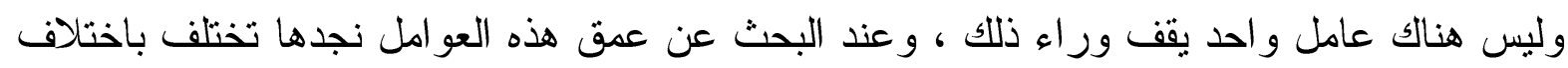

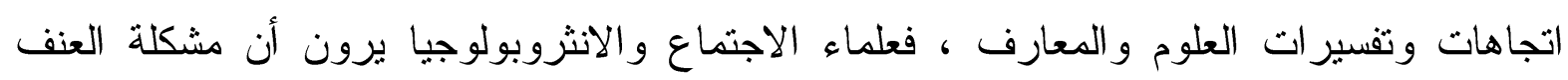

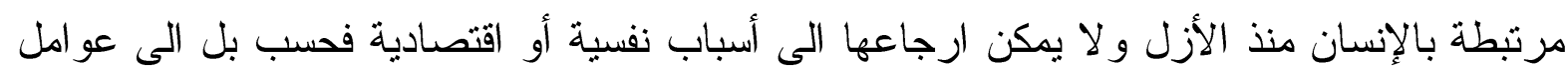
أسهوت في بروزها، فالعنف يختلف باختلاف الأفكار و الثقافات و الأنظمة و المر احل التاريخية.

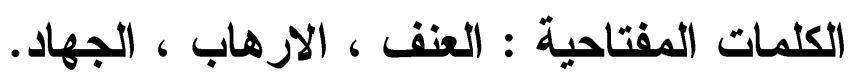




\title{
Violence and Terrorism
}

(Socio-Anthropological study in Baghdad/Al Doura A case Study)

Asst.Instructor. Sanaa Salih Abd Ali

University - college of Arts -Department of Anthropology and Sociology

E.mail: sanaasaleh@uomustansiriyah.edu.iq , sanaay80@yahoo.com

Received : $1 / 6 / 2019$

\begin{abstract}
Violence and Terrorism are regarded the biggest problems facing societies in our modern world. The size of this problem varies from one society to another according to the culture and characteristics of each society. The manifestations of violence and terrorism today are among the most serious phenomena that threaten the human security of all societies at the international and international levels.
\end{abstract}

Violence and terrorism by the armed groups in our new Iraq after 2003 are one of the most serious problems faced by society in our contemporary history, which resulted in tens of thousands of victims of different sects and religions in Iraq. This phenomenon leads us stop and discuss, the violence has become a source of concern and the security, technical, social and political threat that we aspire to enjoy compared to the rest of the stable peoples (politically and economically).

The search for the factors of armed violence and terrorism is a hard task. There is no single picture of violence. There is no single factor behind this. The search for the depth of these factors is different according to the different directions and interpretations of science and knowledge. The sociologists and anthropologists believe that the problem of violence is linked to man since eternity, and it can't be traced back to psychological or economic reasons, but to factors that contributed to their emergence. Violence varies according to different ideas, cultures, systems and historical stages.

Key words: Violence، Terrorism، Jihad.

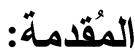

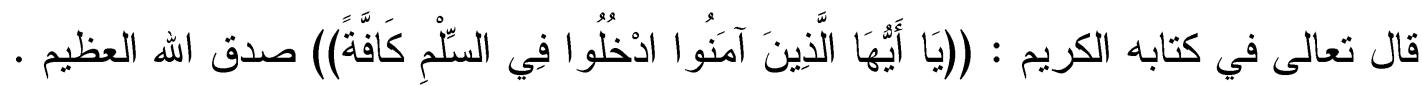

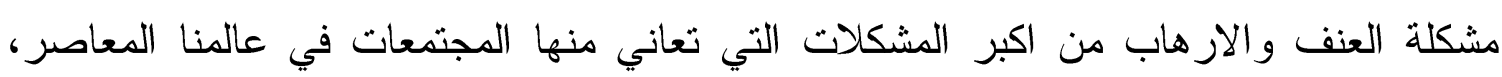

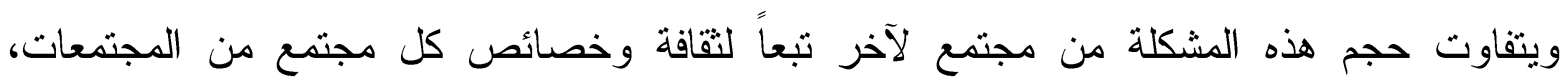

$$
\begin{aligned}
& \text { فمظاهر العنف والارهاب تعد اليوم من أبرز الظواهر الخطيرة التي تهدد الامن الانساني للمجتمعات } \\
& \text { كافة، لذا اصبحت موضع اهتمام كبير على المستوى الدولي و العالمي . }
\end{aligned}
$$


بسبب القلق المتز ايد لهذه المجتمعات من الهجمات المسلحة والاتتحارية التي تتعرض لها بلدانهم بين مرحلة و أخرى مخلفة الآلاف من الضحايا فضلاً عن الدمار والخراب الذي تسببه هذه الهجمات. و المجتمع العر اقي اليوم هو أحد هذه المجتمعات التي تعيش حالة العنف والارهاب المسلح الذي ظهر

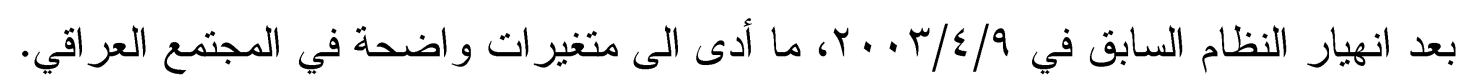
برزت أكبر معالم هذا التغيير في حالة الفوضى والاضطر اب وفقدان المعايير فضلاً عن العنف الطائفي في ظل الصر اعات السياسية والتخخلات الاقليمية وظهور الميليشيات المسلحة، هذا كله قد أدى الى قلة التماسك الاجتماعي بين مكونات المجتمع وتزعزع التقة بالآخر. و ظهور هذه المظاهر زاد الوعي بمخاطر العنف وآثاره السلبية على بنية المجتمع العراقي. جاءت دراستتا هذه محاولة للإحاطة بهذه المشاكل من خلال التعرف على جذورها ومرجعياتها وصور ها المختلفة، ومن ثم تشخيص دو افعها و الأسباب المؤدية لها و الظروف التي اسهمت في ازدياد حدتها بهدف التوصل الى المقترحات و التوصيات التي من شأنها الحد من هذه الظاهرة. لذلك سنحاول في هذه الدر اسة الكثف عن هذه المظاهر بشكل و اقعي ومن ثم تحليلها وتفسير ها. الفصل الاول : عناصر الدراسة النظرية ومفاهيمها العلمية

المبحث الأول / عناصر الار اسة :

أولا: مشكلة الاراسة (study Problem) : في الدراسة الانثروبولوجية تكون هناك تساؤلات للار اسة تهدف الى معرفتها و التوصل الى الاجابات عنها من الميدان وفي دراستتا الحالية تساؤلات عديدة منها:

$$
\text { 1- ما العو امل و الأسباب ور اء العنف في العراق بعد عام ب . . بم؟ }
$$

ץ- - هل حالة العنف في العراق قد خلقتها الظروف و الأزمات المتكررة في البلاد؟ ب- ما أبرز الجماعات التي تقف ور اء العنف و العمليات الانتحارية في العراق؟

$$
\begin{aligned}
& \text { ع - هل العنف الذي يستهدف الابرياء من العر اقيين جهاد أو ارهاب؟ } \\
& \text { 0- هل الطو ائف العر اقية تجيز استخدام العنف ضد الآخر؟ } \\
& \text { ؟- ما الأداة الأفضل لمنع دخول قوات الاحتلال من البلاد؟ } \\
& \text {-V } \\
& \text { - - هل تعدد الطو ائف في العراق بحفز نشوء العنف؟ }
\end{aligned}
$$


9- لماذا تعد الدورة من المناطق التي شهدت ارتفاعاً في مستويات العنف؟ • 1- هل ما زالت هنالك مظاهر عنف في منطقة الدورة؟

\section{ثانياً: أهمية الارسة (Study Importance) :}

تتتاول هذه الدراسة موضوعاً مهماً وخطبراً في الوقت نفسه ، فهو لم يلق اهتماماً كافياً من

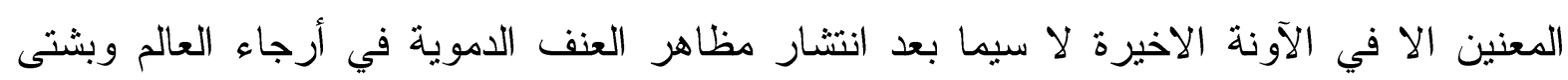

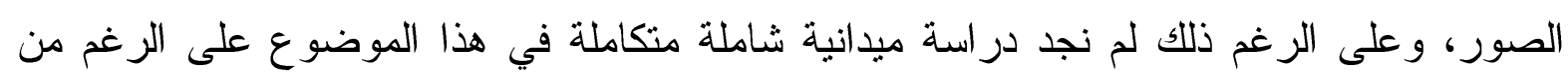

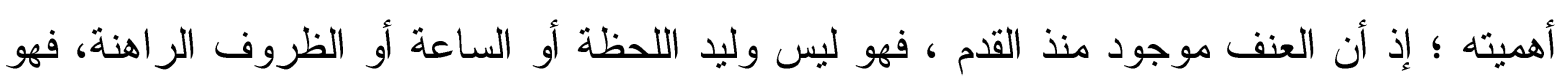

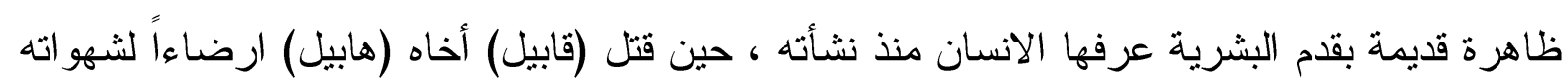

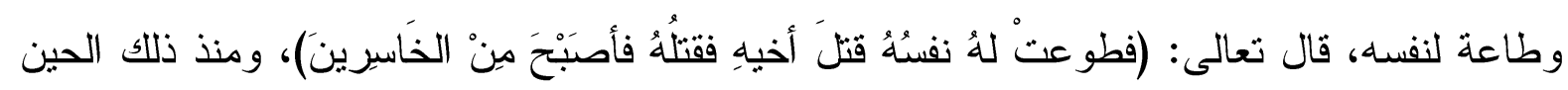
برزت مظاهر العنف والعدوان البشري وتتوعت من حيث طبيعتها أو شدتها و آثارها على الفرد

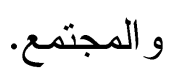
أما الاعتبارات العلمية فتتمثل في أنه بحث بعالج موضوعاً حيوياً بقصد الوقوف على حجم

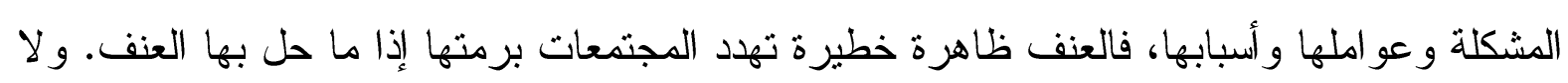
أبالغ عندما أقول إن العنف والإرهاب أصبح حديث مجتمعنا في الصباح و المساء ، و الأمن والاطمئنان هدفه المنشود. ثالثاً: أهداف الدارسة (Study objectives): نسعى من خلال دراستتا الى معرفة جذور العنف والارهاب في المجتمع العراقي و آثارها في حياة الفرد و المجتمع في المرحلة الحالية. إذ أن دراسة هذه الظاهرة وتحليلها ليس سهلاً، بل ينطلب دراسات مستفيضة لمعرفة الحقائق العلمية المتعلقة بالعنف.

رابعاً : صعوبات الاراسة : لقد واجهت اثثاء عملية البحث بعض الصعوبات، وكانت بحسب الآتي : 1- قلة الدراسات العر اقية الميدانية التي تتاولت موضوع العنف و الارهاب من حيث تاريخه وجذوره و العو امل المؤدية اليه سواء في علم الاجتماع او الانثروبولوجيا. ץ- عدم وجود احصائيات متكاملة عن نتائج العنف سواء في المؤسسات الحكومية التي تمكنت من الوصول الى بعضها أو منظمات المجتمع المدني ومو اقع الانترنت. 
ب- البيانات التي توصلت إليها من مصادرها أو من مواقع الانتزنت اغلبها بيانات خاصة او فيها شيء دن السرية و لا يمكن اعطاؤها بسهولة، واحتجت لوقت ليس بالقليل مع جهد كبير منو اصل

$$
\text { حتى تمكنت من الحصول على بعضها. }
$$

ع- من صعوبات البحث أن الامن في هذه المنطقة ما زال هشاً فهاك بقايا لبعض العمليات الارهابية و الحواضن المقلقة لأمن المنطقة، لكن بالتعاون مع معارف ومتعاونين هناك، تخطي هذا العائق

$$
\text { لاستكمال البحث الذي استمر العمل فيه لسنوات طو ال. }
$$

ه- عدم استجابة بعض الافراد في منطقة الدراسة أثناء المقابلة معهم، إذ لا يز ال هنالك مخاوف لدى

$$
\text { الباحثين من التطرق الى هذهِ الموضوعات. }
$$

اولاً: الثقافة (Culture):

التقافة في اللغة، هي من تثقف الثي تقفاً وثقافاً وثقوفه أي حذقه، ورجل ثقف أي حاذق فهم أو سريع التعلم ، و الثقافة عند العرب: أي حديدة تكون مع الأقواس والرماح يقوم بها الثيء المعوج.

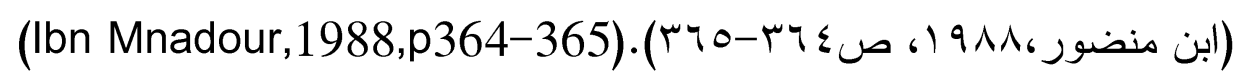

يتفق علماء الانثزوبولوجيا الثقافية (Cultural Anthropology) على أن الثقافة هي موضوع علمهم لكنهم يختلفون في تعريفها ، فقد احصى العلماء ما يزيد عن (0.01) تعريفاً لمفهوم الثقافة، إذ قاموا بجمع عدد كبير من التعريفات (وصفية- سيكولوجية- بنائية)، وفي نهاية القرن التاسع عشر كان هناك اتفاق على الأخذ بالتعريف المشهور الذي وضعه الانثروبولوجي البريطاني (ادورد تايلر)(Edward Tylor) في كتابه (الثقافة البدائية) (Primitive Culture)، وعرف الثقافة بأنها: (ذللك الكل المركب الذي يشتمل على المعرفة و العقائد والفنون والاخلاق والقانون و العادات وكل

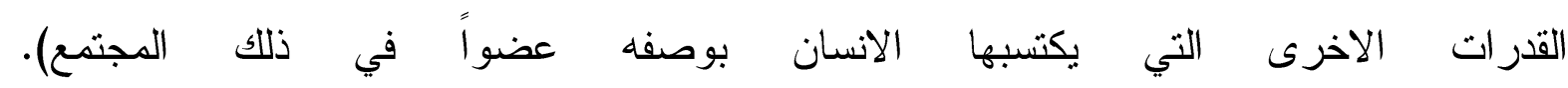

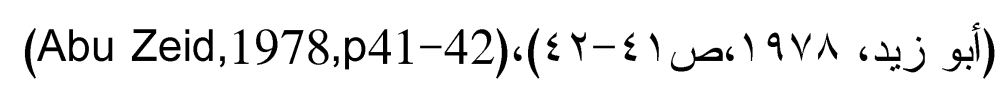
ثانياً: العنف (Violence): صعوبة تعريف العنف أمر بعاني منه بصورة خاصة علماء الاجتماع والانثروبولوجيا ـ لأنه يختلف من مجنمع لآخر ومن ثقافة لأخرى ففي نظام افريقي معين يعد تقديم الذبائح البشرية امراً 
طبيعياً ولا يمكن وصفه بالعنف لذا فإن العنف يتعلق بنظام معايير الجماعات وفي هذا الأمر يجب معرفة نظام القيم الذي يتبناه مجتمع معين.

ا ـ المفهوم اللغوي: العنف في اللغة مأخوذ من الجذر اللغوي (عنف) ويعني كل فعل أو سلوك يتضمن الثدة أو التوبيخ فهو الخرق بالأمر ، وقلة الرفق به، وهو ضد الرفق ويعني الاستخدام غير المشروع للقوة المادية بأساليب متعددة لإلحاق الاذى بالاشخاص او الاضرار

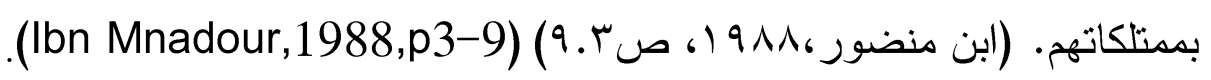
r. المفهوم السياسي: يعرف العنف سياسياً (Political Violence) ، بأنه أعمال التمزيق و التثمير و الاضر ار كافة ويكون غرضها واختيار أهدافها أو ضحاياها وآثار ها ذا دلالات سياسية. ويعرف ايضاً بأنه: التهديد في استخدام القوة لتحقيق أهداف سياسية بشكل يأخذ الأسلوب الفردي أو الجماعي السري أو العلني المنظم أو غير المنظم. (زحلاوي، 9 (، صبره).(

(Zahlawi, 1980,p82

ثالثاً: الإرهاب (Terrorism) : يعد الارهاب في عالمنا اليوم من أبرز مظاهر العنف المسلح حتى أن عبارة (الحرب ضد الارهاب) و (مكافحة الارهاب) تعد من أكثر العبارات تداولاً في الأدبيات السياسية نظرًا لخطورته على حياة وأمن شعوب العالم وتأثيره السلبي على الصعد كافة والمستويات . من هنا نالت هذه الظاهرة اهتماماً اقليمياً ودولياً الا أن المشكلة التي تواجه الباحثين في شتى المجالات هو صعوبة تعريف ثابت أو جامع للإزهاب . نظراً لتعدد أشكاله ودوافعه ومنطلقاته ، إذ أن أعمال العنف عند بعض الدارسين تعد مقاومة وحقاً مشروعاً، له مسوغاتها ومبرر اتها بينما تعد هذه الاعمال نفسها ارهاباً و اجر اماً و انتهاكاً في نظر آخرين مهما كانت مبرر اتها.

تاريخ عبارة (الارهاب Terrorism) لا تتعدى بدايتها نهاية القرن الثامن عشر أبان الثورة الفرنسية وتحديداً عام ؟ \ام وكلمة الارهاب مشتقة من (الرهبة Terrier) وهي بمعنى (يرتعد أو يرتجف) فهي تشير الى الخوف والاضطر اب أو الخطر القريب. وقد وردت لفظة الارهاب في القرآن الكريم بصيخ و اشتقاقات مثل (ير هبون ، فار هبون ، رهباً ، الرهب ، استر هبهم ). 
أما الارهاب في الاصطلاح السياسي فإنه: محاولة لنشر الذعر والفزع لأغر اض سياسية وهو

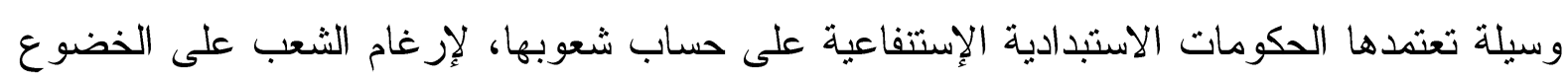
و الاستسلام و إثناعة الرضو خ لمطالبها التعسفية .

أما تعريف الامم المتحدة فهو: الاعمال كافة التي تعرض أرواحاً بشريةً بريئةً للخطر او تهدد

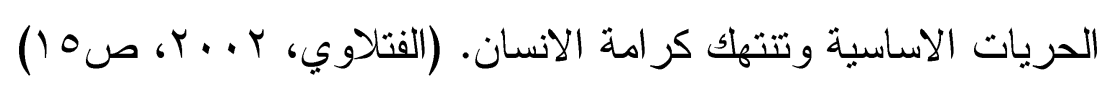

( Al-Fatlawi, 2002,p15)

رابعاً: الجهاد (Jihad): (1) (1)

الجهاد في الاصطلاح، يعرفه العلماء بأنه استفراغ الواسع في مرافعه العدو ،وللجهاد ثلاثة أصناف هي:

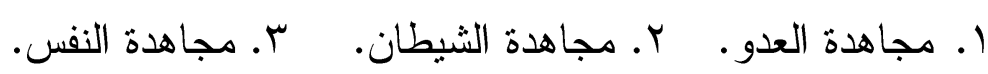
وتدخل الاصناف و المعاني جميعها تحت (قوله تعالى) : "وجاهدوا في الله حق جهاده هو اجنباكم وما جعل عليكم في الدين من حرج ملة ابراهيم خو سماكم المسلمين من قبل وفي هذا ليكون الرسول شهيداً عليكم وتكونو اشهداء على الناس فأقيموا الصلاة واتو الزكاة واعتصموا بحبل اله هو مو لاكم

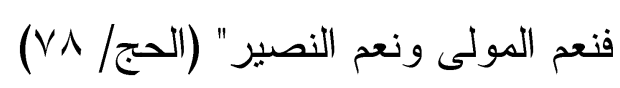
ما يؤكد هذا التتوع في مفهوم الجهاد أن الرسول الاكرم (ص) قال بعد قدومه من إحدى الغزوات

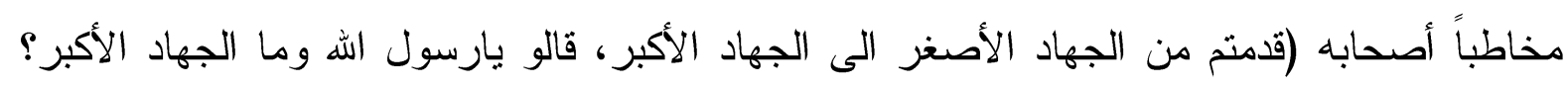

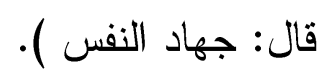
قاعدة الحرب و الجهاد وفق النظرية الاسلامية هي قاعدة استثائية ذات موارد محددة ومشروطة ، فالأصل في العلاقات الانسانية هو السلام والتعاون بين الثعوب كافة، وكما يقول تعالى: "يا أيها الذين امنو ادخلو ا في السلم كافة و لا تتبعو ا خطو ات الثيطان إنه لكم عدواً مبينا"(البقرة/N • ب) فلا يجوز القتال وشن الحرب على الاخرين في نظر الاسلام الا في حالات معينة، كالدفاع عن النفس

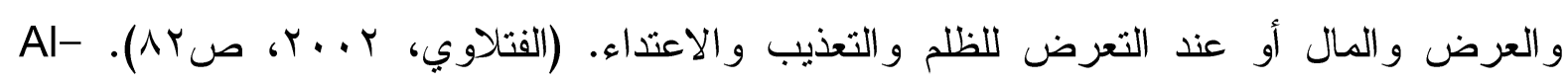

(Fatlawi, 2002,p82) 


\section{خامساً: المقاومة (Resistance):}

على الرغم من أن مفردة المقاومة محدودة الاستعمال و التداول في معاجم اللغة الا أنها مشتقة من الفعل (قَوَمَ) ، قال ابن منظور في لسان العرب : ما زلت أققاوم فلاناً في هذا الأمر أي أنازعه. فهي تأتي بمعنى المنازلة ، و الوقوف بوجه الطرف الآخر .

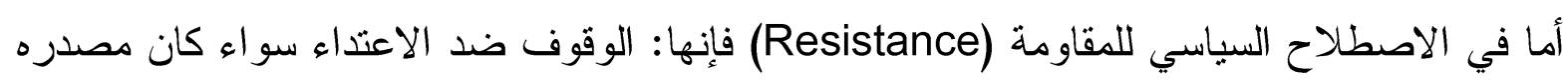
قوة اجنبية غازية أو قوة داخلية مستبدة . و عرفت الموسوعة السياسية (المقاومة الشعبية): كافة أعمال الرفض السياسي وغير السياسي التي يقوم بها شعب من الشعوب ضد مختلف أثكال الاستعمار و الاحتلال و الطغيان على وطنه ومصالحه. و المقاومة المسلحة مصطلح حديث ارتبط بوجود القوة الاستعمارية في البلدان العربية والاسلامية وممارساتها التعسفية ضد ابناء تلك البلدان. فالمقاومة بأشكالها السلمية و المسلحة كافة هي حق مشروع لكل الدول و الثعوب التي تعاني من الظلم الداخلي والاحتلال الاجنبي بالاستتاد الى حق تقرير المصير الذي تستند اليه المقاومة في

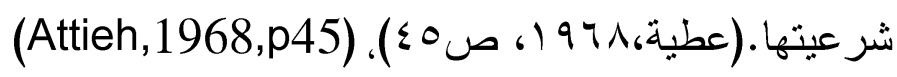
سادساً: الاحتلال (Occupation): يظهر الاحتلال عندما تقوم الدولة بإستخدام قو اتها المسلحة للهجوم على دولة اخرى وقد نجحت هذه الدولة باحتلال (جزء أو كل) من إقليم دولة وقع عليها الهجوم ، فهو هجوم مسلح مضاف اليه

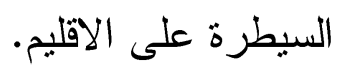

من هنا يوصف القانون بالمقاومة ضد الاحتلال بـ (الثوار) ويطبق عليهم القانون الدولي في عمليات مقاومتهم للاحتلال. وهذا حق شرعي وقانوني للشعوب اذا ما حصل اعتداء على أمنها وحريتها

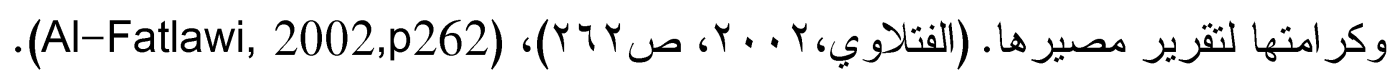
ومن خلال اطلاعي ودراستي لهذا الموضوع بشكل معمق أستطيع أن أحدد عدة فروق بسيطة بين معنى مفهومي (الار هاب) و (الجهاد) ومن هذه الفروق. 


\begin{tabular}{|c|c|}
\hline 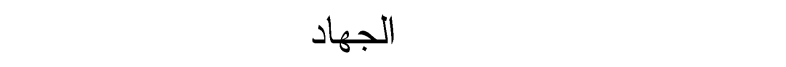 & 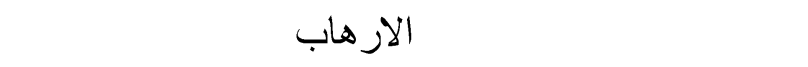 \\
\hline ا. دينه الاسلام ومصدره القر آن و السنة النبوية. & 1. لا دين له ومصدره التشدد و التطرف. \\
\hline r.غايته الدفاع عن الاسلام و المسلمين و لا يشرع الا & r. غايته اشـاعة الرعب و الخوف و الدمار . \\
\hline في حالة وقوع الاعتداء. & r.عمله سري وقائم على اساس الغدر و الخيانة ويقتل \\
\hline r.عمله علني و لا يعتمد على الغدر و الخيانة و لا يقتل & حتى المشتبه بهم. \\
\hline أحد عند الاشتباه به. & ع. لبس لديه قيادة موحدة، بل هو عبارة عن جماعات \\
\hline ع. يعلنه (إمام المسلمين) او حاكمه الثرعي فهو & مسلحة ومتطر فة. \\
\hline عمل جماعي لا فردي. & \\
\hline
\end{tabular}

\section{الفصل الثاني : إطار الاراسة المرجعي}

\section{المبحث الاول / العنف في الفكر الاتثروبولوجي:}

لقد حظي موضوع العنف بإهتمام العديد من علماء الانثروبولوجيا والاجتماع ابتداءاً من (ابن

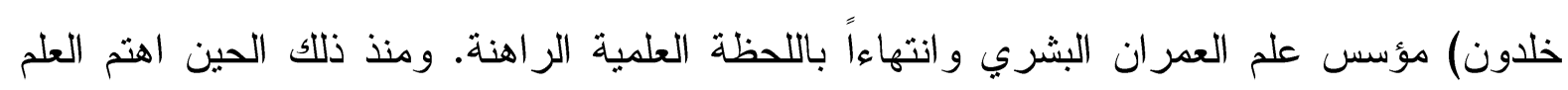

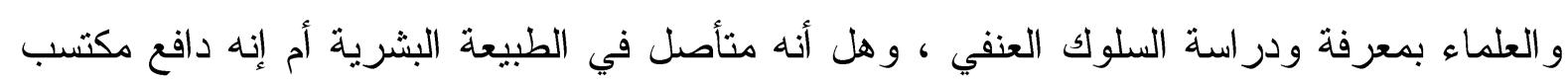
من البيئة المحيطة بالإنسان. ويأتي هذا الاهتمام بالعنف لأن معركته لا زالت قائمة ومستمرة وعلى الرغم من نطور الانسان

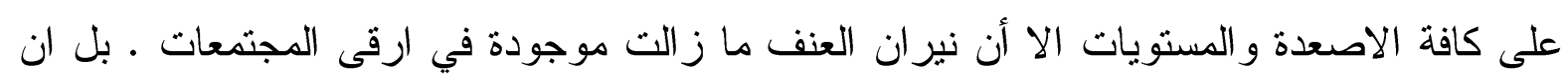
الحضارة الجديدة ساهمت بشكل او بأخر بإزدياد اعمال العنف وطورت من ادوات واساليب العنف و الجريمة، اذ استطيع ان اقول ان العنف هو التهديد الاكبر لا من الانسان بكل صوره و اشكاله. فأمن

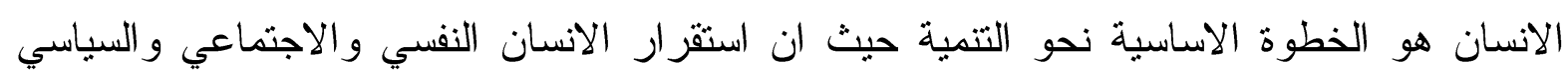

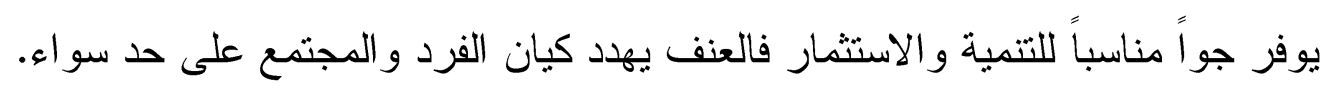
من هنا جاء اهتمام رجال الانثروبولوجيا والاجتماع بهذه الظاهرة التي صاحبث الانسان و لازمته في وجوده على الرغم من تغير الزمان و المكان والثقافة ، وقد جاءت هذه الآراء و التفسيرات للعنف مختلفة و أهمها: 
ا. ابن خلدون: يرى أن العنف نزعة طبيعية وأنه جزء من الطبيعة البشرية ، ومن أخلاق البشر الظلم و العدوان وأن الصراع هو هجوم البدو على الحضر ، وتعني العصبية القبلية. (الالتحام

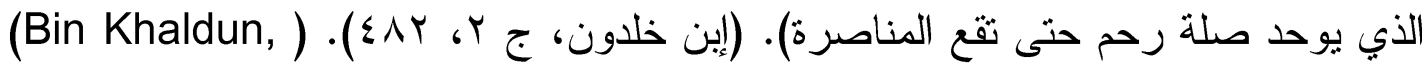

$$
\text { C } 2 ; 482
$$

r. نيتشه: يعتقد أن الحياة الاجتماعية مستمرة في التغير والتغيير وأن حباة الانسان لا تستطيع أن تحيا الا على حساب حياة أخرى ،لأن الحباة والنمو والرغبة في زيادة الاقناء تكون عن لهن طريق السطو و الاستيلاء على الآخرين ، وهذا ينطلب استعمال العنف لاستغلال و اغتصاب حقوق الاخرين فمنطلق الحياة ، العنف و القوة و التسلط و الاخضاع. r. فردريك أنجلز: أوضح أن نظرية العنف ظهرت خلال الشرح المكرس للاقتصاد السياسي وأن الاستعباد يشكل المنشأ لمجمل التاريخ وان الملكية المؤسسة على العنف بقيث سائدة الى يومنا

$$
\text { هذا و هي مؤسسة تقوم على العمل الإستعبادي البدائي. }
$$

ع.كارل ماركس: انصب اهتمامه على العنف الثثري ومن خلاله تتاوله للصر اع ربط ماركس بين كل من التغيير والصراع مؤكداً على الدور الايجابي الذي يؤديه العنف في حركة التاريخ فالصر اع يشير الى وجود خلل في البنى الاجتماعية أما العنف فهو شرط أساسي لتجاوز هذا الخلل و لإحداث هذا التغير، فهو الاداة التي تحل بوساطتها الحركة الاجتماعية مكانها وتحطم اشكالاً سياسية جامدة وميته. ه. أميل دوركهايم: أكد أن العنف ظاهرة ثقافية أتت مع رياح التطور الاجتماعي ومع تحول المجتمعات الانسانية كم مجتمعات بسيطة الى مركبة. (زحلاوي، 9101، صب ا). (Zahlawi, 1985,p12) ومع تز ايد و اتساع المعلومات الانثروبولوجية شيئًا فشيئًا تز ايد الاقتاع العلمي للباحثين بأن العنف من ثوابت الو اقع الانساني بغض النظر عن تعدد اشكاله وتفاوت مستوياته. وهذا الانطباع قائم على احصائيات جرائم العنف والقتل والاعتداء الذي ازداد في عالمنا المعاصر منذ الثورة الصناعية و الحضرية الحديثة وتعقد الحياة معها. فالعنف في عالمنا اليوم يمثل اطروحة كبرى في علم الاجتماع و الانثروبولوجيا ،لأنه يتعلق بالانسان وصر اعه مع غيره .(جميل، V.... Jamel, ) ص II). 
المبحث الثاني / مرجعيات في الثخصية العر اقية: كثير اً ما يقال عن الثخصية العر اقية أنها شخصية (طيبة ومحبة للخير والسلام ، وعطوفة وغيورة، ومتسامحة وكريمة وصبورة وغيرها من الصفات الخلقية الرفبعة)، لكن على الرغم هذه الصفات الحميدة في الثخصية العر اقية، فإن ذوي الاهتمام بهذا الموضوع ، اثثتو امن خلال در استهم

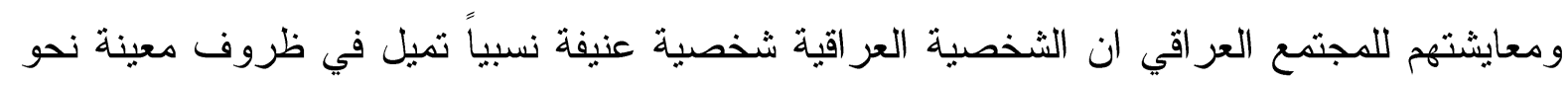
العنف والاعتداء على الآخر لافتقارها الى ثقافة الحوار الجيد الهادئ بالتعبير عن مطالبها. و الغالبية لا تعترف بالخطأ حال وقوعه ، خالقة شتى الاعذار و المسوغات لذاتها (الانا الاعلى) في ممارسة العنف. فالعنف حاضر بقوة في بلادنا ومجتمعنا على مر العصور بل هو حاضر حتى في حواراتتا

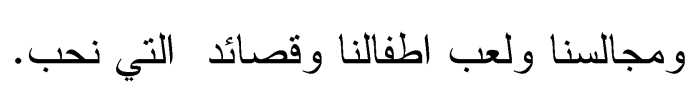

المتمع العراقي ليس متفرداً بظاهرة العنف ، بل إن هناك مجتمعات يثكل العنف سمة ثقافية

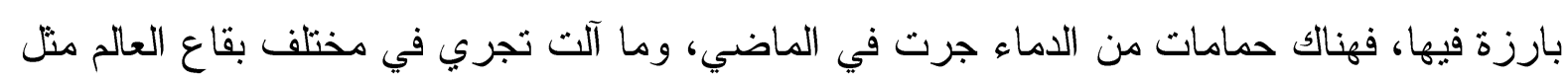

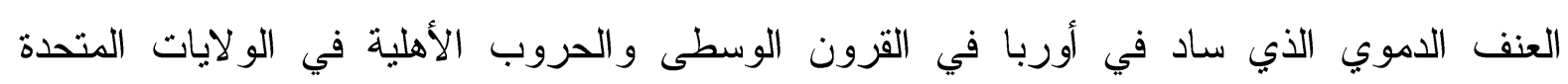
الامريكية و الجز ائر ولبنان و افغانستان وباكستان و غير ها من الدول.

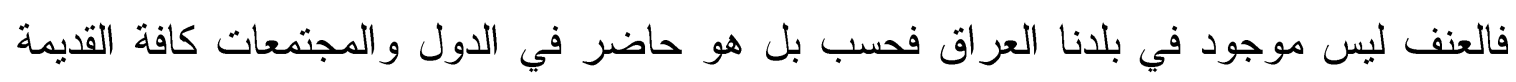

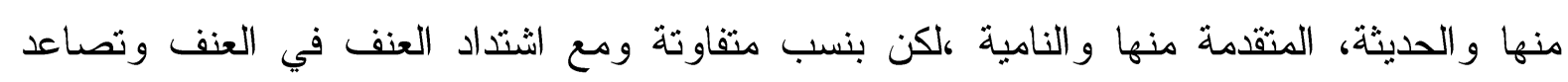

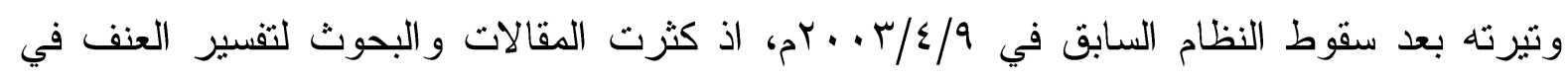
العراق ، وظهرت أبرز مرجعيات العنف في العراق حسب أداء العديد من المفكرين و العلماء بأنها لا لأل تعود فقط الى (صر اع البدو و الحضر) فحسب بل ان هناك أسباب أخرى أقوى وأثد نأثيراً من هذا.

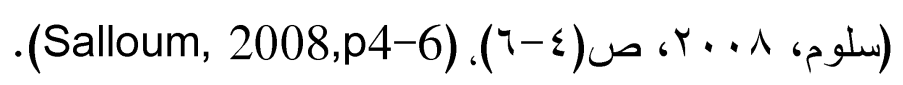

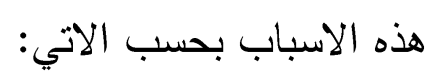
ا. الصر اع على السلطة: البذرة الاولى للعنف في الثخصية العراقية كان بعد ظهور الاسلام حسب

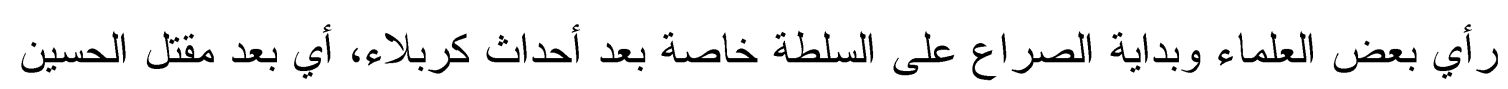

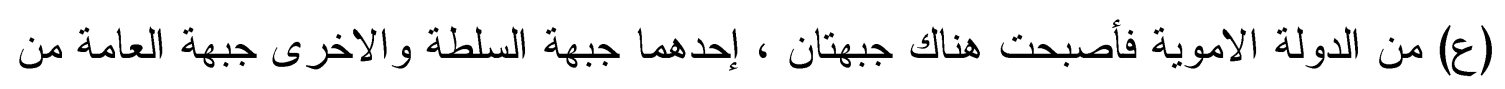

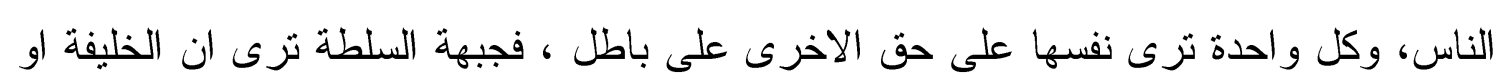

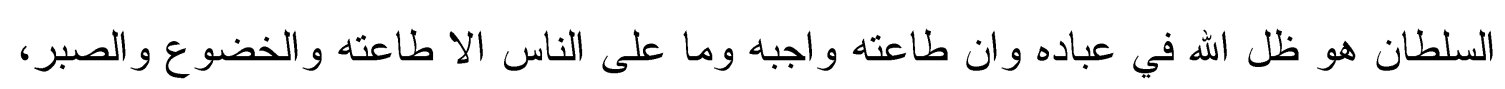


و هكذا لوت السلطة الدين وجعلته في خدمة السياسة ، أما جبهة العامة من الناس فترى أن السلطة مغتصبة للحكم وأن الاطاحة بها واجب لأنهم ارتكبو الظلم و الاضطهاد بحق الناس، وقد حرجوا على تعاليم الدين، ومن هنا نشأت قطيعة بين الجبهتين (السلطة والناس). بذلك مارست السلطة ثقافة العنف و القتل و الرعب، بل لاقى العر اقيون أثد ألوان القتل والصلب و التقطيع و التمثيل بالجثث، ويشير التاريخ الى أن السلطات التي تعاقبت على العراق قد سفكت دماء العر اقيين لأكثر من ( . . r I) سنة حتى ان بعض من حكموا العراق كان لديهم في قصورهم خزائن كانت تحفظ بها رؤوس خصومهم و أعدائهم بعد قتلهم. ( الصالح، ^ ... ب). (Al-Saleh2008, at http://www.radiodijla.com)

r. الصراع الطائفي في العراق : يتولد هذا النوع من الصراع من خلا الاقصاء الطائفي أو التهميش لطائفة معينة من السلطة وإبعادها عن مر اكز الحكم والقرار السياسي أو يكون نتيجة تصارع دولتين مختلفتين في العقيدة ، وهذا ما ابتلى به العر اقيون إذ ان الصراع الطائفي كان موجوداً في العراق منذ صدر الاسلام. ب. وجود الاجنبي: تثير احتلالات المتكررة على العراق الاحساس بالذلة والاهانة عند ابن البلد، ما يدفعه الى رد الاعتبار النفسي و الوطني ، وذلك من خلال العنف ضد المحتل أو المتعاونين معه بالسلطة و المصالح و التاريخ. (الصالح، ^ . . ؟)، (Al-Saleh2008,at http://www.radiodijla.com) المبحث الثالث / مؤشرات العنف في المجتمع العر اقي بعد عام ب . . بم : شهد العراق بعد انهيار السلطة في عام ب . .بم عنفاً منقطع النظير، إذ تحول العنف من (السلطة تجاه المجتمع) وبالعكس الى عنف بين مكونات المجتمع العراقي. إذ اتخذ العنف طابعاً طائفياً وسياسية لا سيما بعد التفجيرات التي حدثت (للمرقدين العسكريين) في مدينة سامراء في

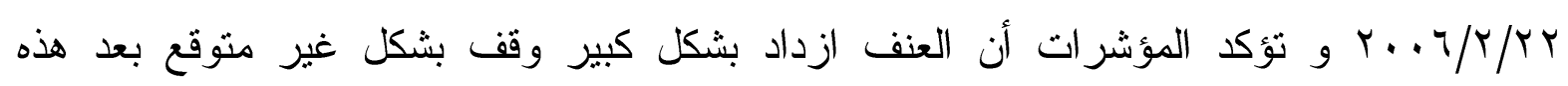
الاحداث الكارثية. و حصد العنف أرواح الآلاف من الناس فنار العنف لا تعرف الرحمة على الصغير أو الكبير ، رجالاً ونساءاً البريء والمدان ، فانتشرت مظاهر العنف في كافة المحافظات العر اقية لتشتمل على المجتمع بأسره بكل أديانه وطوائفه ومذاهبه وقومياته الا أن العنف كان نتيجة الخسارة والكل به خاسر. ويتضح من خلال المؤشرات والبيانات، أن الاعوام

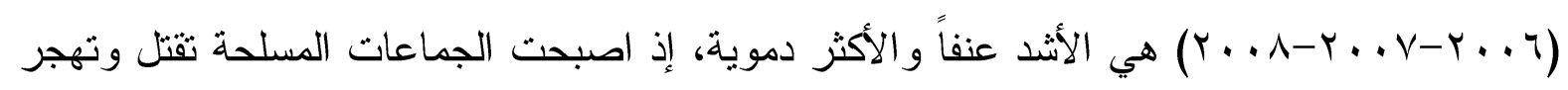


على الهوية و الانتماءات الطائفية و المذهبية و العرقية ، فأصبحت لدينا مناطق عنف ساخنة يسكنها مختلف الاطياف العراقية وهي المناطق التي تتوجد فيها الجماعات المسلحة والخارجة عن القانون التي تتخذ هذه المناطق قاعدة لشتى عملياتها ذات الطابع الطائفي. أما بعد ^ . . ب فالمؤشرات تدل على انخفاض مستوى العنف المسلح نسبياً نتيجة خطة فرض القانون و العمليات الامنية ضد المسلحين والقيام بعمليات المصالحة الوطنية بين مكونات المجتمع العر اقي ومساندة العشائر العراقية الأصلية لقوى الامن من خلال تشكيل مجالس الصحوات لمواجهة جماعات العنف في المناطق الساخنة وهذا ما حصل بالفعل في (بغداد- ديالى - الانبار - الموصل صلاح الدين ) ، الى مدة تجدد العنف بعد فاجعة سبايكر وما تلاها من سقوط مدن كاملة تحدت سطوة العصابات المسلحة تحت مسمى الدولة الاسلامية في العراق (داعش) وهذه المدن هي : الموصل وصلاح الدين و الانبار وديالى بعد أحداث جزيران ع ا . . . القصل الثالث : الاطار المنهجي للار اسة

المبحث الاول / الاطار المنهجي للار اسة: اولاً: منهجية الدر اسة: لا يمكن لأي باحث ان يقوم بأي دراسة علمية من غير أن يتبع منهجاً معيناً

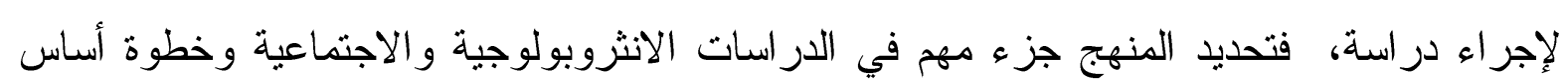
من خطو ات البحث العلمي. و المنهج ترجمة للكلمة الفرنسية (Method) التي ترجع في الاصل الى الكلمة اليونانية (Ueqoos) و يستعملها الفيلسوف اليوناني افلاطون بمعنى البحث أو المعرفة. فالمنهج هو الطريقة التي يتبعها

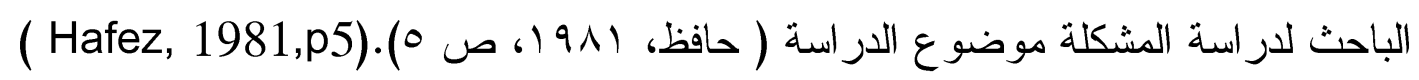
ويهتم المنهج بعدد من القواعد والمعايير التي توضع من أجل الوصول الى الحقيقة لذلك فهو يمثل جوهر العلم وبدونه يستحيل الوصول الى المعرفة الصادقة الموضوعية.(حافظ، (919 (، صم () ) (Hafez,1981,p18) و لأهمية موضوع الدراسة وتداخلاته، استخدمنا أكثر من منهج واداة للبحث في خطوة للإحاطة به بشكل دقيق، وجمع البيانات عن هذا الموضوع ، ومن أهم هذه المناهج المستخدمة هي : 


\section{1. منهج الفهم الاتاتي و التحليل المعرفي (Ethnos Science) :}

يعد هذا المنهج من أهم المناهج في الفكر الانثروبولوجي الذي يرنكز على اكتثاف الطريقة التي

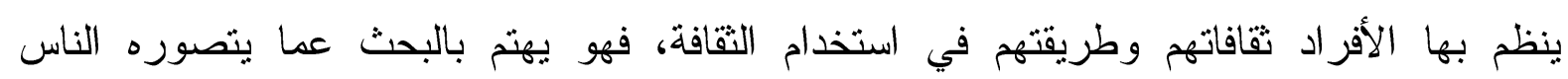

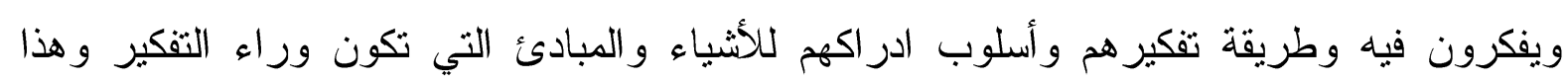
التصور .

إذ أن الانسان من خلال المعرفة يبني لنفسه عالماً معقو لاً يصف فيه الاشياء المختلفة والمتعددة. و المنهج المعرفي وما يسمى بمنهج الفهم الذاتي يعد منهجاً انثروبولوجياً معاصراً يستخدم في دراسة لأسة الظو اهر و الثقافات في المجتمعات المعاصرة. قد تبلور هذا المنهج ما بعد البنائية الوضعية في منتصف القرن العشرين بسبب تغير العالم

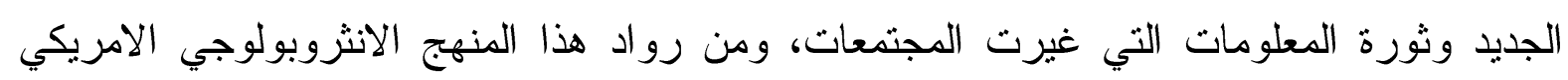

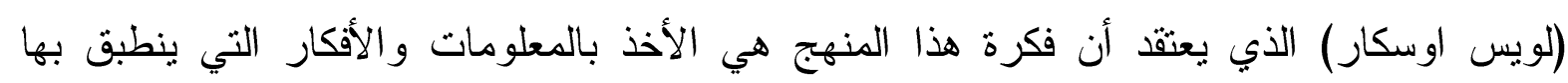
المبحوثون ومدركاتهم العقلية للأشياء دون اسقاط الباحث مكونه البنائي عليهم.

قد وضفنا هذا المنهج لمعرفة الكثير من مظاهر العنف المسلح في مجتمع الدراسة وأبرز العوامل و الأسباب التي تقف وراء العنف المعاصر كما يعتقد المبحوثون ووفقاً لبنائهم المعرفي في فهم الثقافة وحيثياتها.

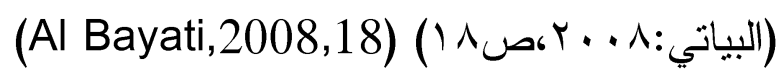

$$
\begin{aligned}
& \text { r. المنهج الوصفي : }
\end{aligned}
$$

يعد من أدق المناهج العصرية الحديثة إذ يعتمد على الوصف الدقيق لمشكلة معينة يتخلاها الغوض و الالتباس في اسبابها و اهدافها واختلاطها بمفاهيم اخرى. فهو يبحث في الظاهرة و مسبباتها و الدخول في عمقها بغية الوصول الى الحلول الناجحة. فالدنهج الوصفي يهدف الى جمع الحقائق و البيانات عن ظاهرة أو موقف معين مع محاولة تفسير هذِ الحقائق تفسيراً كافياً. و لا تتحصر أهداف الدراسات والبحوث الوصفية في مجرد جمع الحقائق وانما تهدف الى تحليل

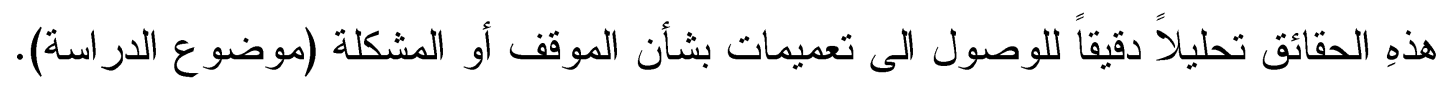

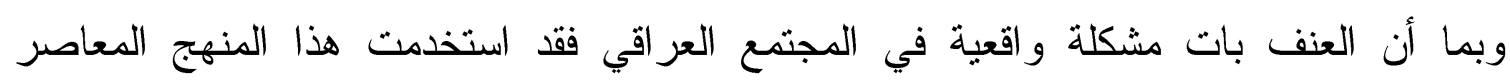

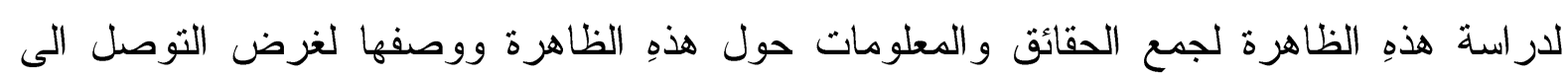


العوامل والاسباب المؤدية الى العنف المسلح ومن ثم وضع الحلول المناسبة لها. .( Hafez, 1981,p140)

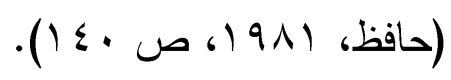
ثانياً: : أدو ات جمع البيانات و المعلومات : تتميز الأبحاث الانثروبولوجية بتعدد الأدوات العلمية لجمع البيانات والمعلومات فقد استخدم علماء الانثروبولوجيا الاو ائل العديد من الأدوات لجمع المعلومات ومعرفة الحقائق ومن أهم تلك الأدوات المعمقة التي سنستخدمها في دراستتا و موضوع بحثنا عن العنف و الارهاب وهذهِ الأدوات بدورها توفر بيانات واسعة عن أي مجتمع او ظاهرة ير اد در استها.

\section{1- الملاحظة Observation}

ترتبط الملاحظة ارتباطاً وثيقاً بالانثروبولوجيا الثقافية والاجتماعية، فهي إدارة شائعة في حياتا اليومية. ومن خلالها نتعلم أثياء كثيرة ، ونستطيع تحديد المواقف واستتاج الادلة فالعلم يبدأ بالملاحظة، والملاحظة العلمية تتمثل في محاولة منهجية يقوم بها الباحث للكثف عن تفاصيل

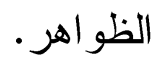

ومن خصائصها المميزة امكانية التكرار فهي مصدر أساس من مصادر الحصول على البيانات، وتزداد قيمة الملاحظة كأداة للبحث العلمي في الموضوعات الحساسة التي يتوقع فيها مقاومة الافر اد لها يوجه اليهم من اسئلة، أو عدم تعاونهم مع الباحث و الامتتاع عن الاجابة أو اللجوء الى تحريفها. فالملاحظة : وسيلة مهمة من وسائل جمع البيانات في البحوث الانثروبولوجية وضرورة استخدامها في الدراسات الميدانية وقد ساعدنا هذا المنهج كثيراً في تسجيل مظاهر السلوك . ( Hafez, 1981,p66)

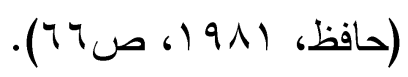

r - المقابلة المعمقة: Depth Interview

تعد المقابلات التي يقوم بها الباحث مع المبحوثثن من اكثر الادوات شيوعاً في الدراسات الانثروبولوجية وحتى السوسيولوجية، إذ أن معظم البحوث في الوقت المعاصر قد اعتمدت على المقابلات المعمقة مع المبحوثين. و المقصود بالمقابلة المعمقة انثروبولوجياً هي مقابلة حرة او مفتوحة بين شخص قائم بالمقابلة وبين المبحوث ، و لا يتقيد فيها بشكليات الاعتماد على كشف الاسئلة المعدة

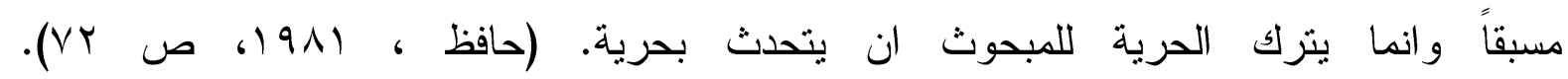
(Hafez, 1981,p72) 
فالمقابلة : هي تفاعل بين الباحث والمبحوث الهدف منها الاجابة على التساؤلات المحددة وصولاً الىى الهدف ، ونجاح المقابلة يتوقف الى حد بعيد على اهتمام المبحوثين بالموضوع، فيشعرون أنهم يؤدون عملاً مفيداً ومن ثم استثارة دو افعهم للاستجابة، وهذا أمر ضروري عند اجراء المقابلة حيث اننا قد استعنا به في بحثنا وقد اثبت فائدته وساعدنا في الحصول على العديد من المعلومات الدقيقة. و المقابلة تتكون من ثالثة أركان أساسية وهي : أ-الباحث القائم بالمقابلة. ب- المبحوث. ج- هدف المقابلة. قد استخدمنا نوع المقابلة الفردية اي مع شخص واحد فقط ــ اضافة الى المقابلة الجماعية أي مع عدة اثخاص في مكان واحد، وهذا وفر علينا الجهد في الحصول على المعلومات لذا فان المقابلة توفر لنا دقة وتعبير عن الرأي الشخصي عن موضوع الدراسة. ثالثًا : نوع العينة وحجمها : إن نوع العينة التي اعتمدناها في البحث هو العينة العشوائية، التي تضمنت مجموعة من الأقارب والأصدقاء وأصحاب المحال التجارية في المنطقة والناس الذين قد تعرضوا هم وأسرهم الى عمليات ارهابية - فضلاً عن أناسٍ كانوا على اطلاع واسع بأعمال المجموعات الازهابية، وقد اختيرت هذه العينة بطريقة تتاسب مع طبيعة الاحياء التي كانت العملية الارهابية منتشرة فيها، وتواصلت الباحثة في الدراسة مع ( •ع) شخصا وهم عينات البحث، وبلغت حالات عدم الاستجابة (V) أغلبها كانت في المناطق أو الاحياء التي كانت ساخنة، وحجم العينة التي قد استجابت (سr) شخصا ، و هذا يتتاسب مع طبيعة المنطقة التي درسناها من الدورة وهي (المهدية

$$
\begin{aligned}
& \text { الاولى - المهدية الثانية - الطعمة). }
\end{aligned}
$$

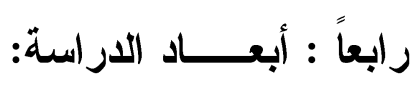

ا- البعد الزماني : وهذا يوضح المدة الزمنية التي استغرقتها في كتابة وتوفير مادة البحث الخاصة بي

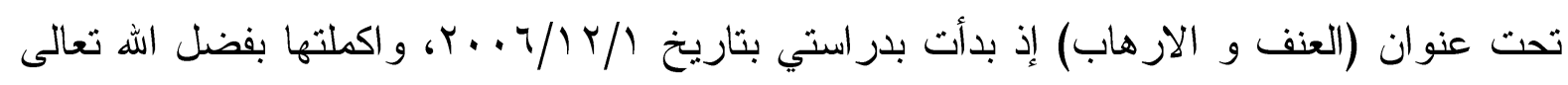

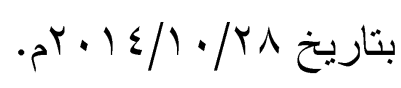

r- البعد المكاني : ويوضح البعد المكاني المنطقة التي تمحورت دراستي حولها، كما موضح في بحثي. اذ اخترت منطقة الدورة، التي اعتمدت منها في دراستي على المهدية الاولى والمهدية الثانية و الطعمة. 
الفصل الرابع : مؤشرات العنف المعاصر في المجتمع العر اقي بعد عام ب . . ب - مدينة الدورة المبحــث الاول / مظاهــر العنــف المسلــح: شهد العراق عبر مر احله التاريخية المختلفة أعمال عنف سياسي و مجتمعي ظهرت آثاره على المجنمع. فالعنف (Violence) قد ضرب جميع مكونات المجتمع العراقي واطيافه، فالعنف في العراق عموماً ليس له هوية ولا يعرف ديناً او طائفة او قومية او منطقة جغر افية معينة. و العنف في (الدورة) قد استهدف الجميع، فضرب الثباب والكبار والنساء والاطفال وعموم الاطياف جميعاً، اذ ضُربَت الجوامع والحسينيات و العامة والنخب و الكفاءات، والاسواق والنباتات و الازقة و الشو ارع و المدنيين و العسكريين و الطلبة و الموظفين...... الخ. فالعنف هي الظاهرة الأبرز هناك، إذ ان المدينة قد اصبحت مدينة أثباح لا يجوب بها إلا المسلحون خاصة في عامي 0 . . ץ-Y . . . فمؤسسات الدولة شبه معطلة هناك. فلا توجد هناك دائرة وظيفية مفتوحة يعمل بها الناس، والأسواق أو محلات البيع إلا قليل و الأهم من ذلك كله عدم وجود در اكز للشرطة لحماية المواطنين وإن وجدت فهي غير فاعلة لقلة عددها وقلة المنتسبين إليها وهذا الوضع الأمني المتردي في المنطقة سمح للجماعات المسلحة بممارسة التهديد والقتل لكل من لا يعمل معهم أو على الأقل لا يؤيدهم رافعين شعار مقاومة المحتل وقتل الخونة و العملاء غطاءاً لهم لكسب المزيد من تأيبد وعو اطف بعض من الناس. فالباحثة هنا ستحاول عرض أهم مظاهر العنف المسلح وما قامت به جماعات العنف في مدينة (الدورة) من عمليات قتل وتهجير وتفجيرات للعديد من الأماكن المختلفة.

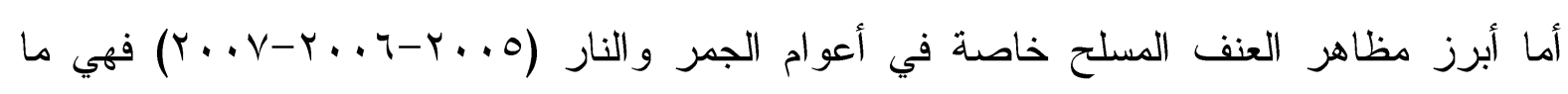

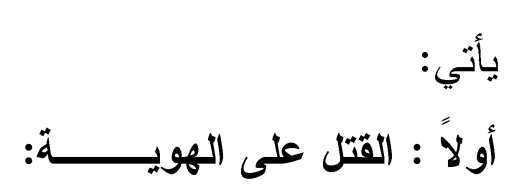
كثيراً ما كانت الجماعات المسلحة تشيع مناخاً من الفوضى والارهاب في مدينة (الدورة) من خلال سيطرتها على العديد من أحياء المدينة فكانت هذه الجماعات تقوم بعمليات قتل مختلفة على أساس الطائفية أو القومية ومن خلال المقابلات التي أجريتها لعدد من المبحوثين ثبين أن العديد من المواطنين الذين يعملون في مدينة (الدورة) قد عملوا بأسماء مستعارة حيث غيروا أسماءهم 
وعشائرهم وبعضهم حمل هويتين أو اكثر الأحوال المدنية خوفاً من الهجمات من الجماعات في

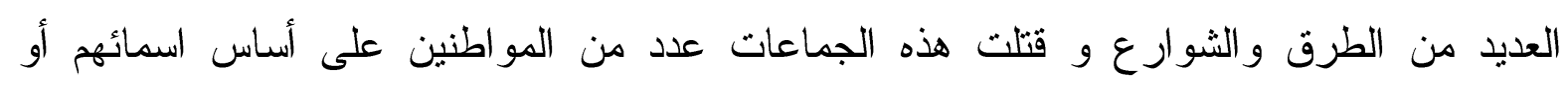
عشائر هم ضناً منهم ان هذا الاسم أو هذهِ العشيرة تمتل طائفة أو قومية معينة أو اتجاه سياسي معين.

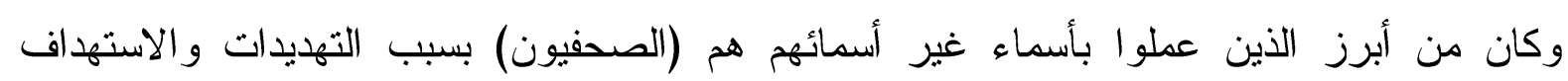
المتكرر ، فقد قتل أكثر من ستة صحفيين هناك. وفي مقابلة أجرتها الباحثة مع أثخاص عملو ا في دائرة الطب العدلي أكدوا أن أغلب من قتلو ا في هني منطقة (الدورة) من المواطنين الأبرياء، وكان يمثل بجثثه من تلك الجماعات أو تضرب بأطلاق الرصاص على الرأس وتهشم جماجمهم، او يذبح الثخص ويقطع رأسه...الخ من مظاهر التعذيب و القتل.

وقد استحصلت بعض الاحصائيات عن آثار ونتائج العنف وما خلفه في هذه السنوات الساخنة ـ وهي كما يأتي:

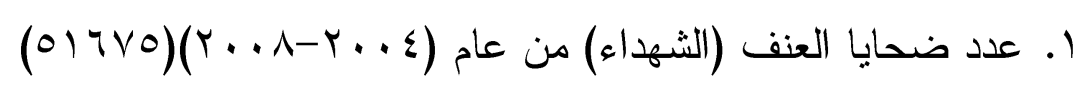

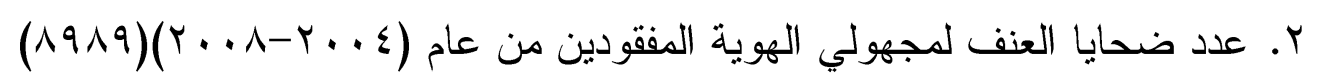

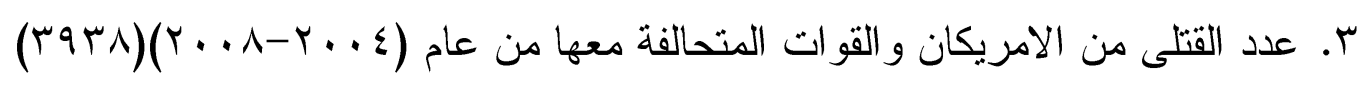

ثانياً : تحريم الانخراط في الأجهزة الامنية العراقية والتهديد بالقتل :

من أجل بقاء الفوضى واستمرارية نشر الرعب والفزع على المواطنين حرمت الإهره الجماعات المسلحة الانتماء الى الاجهزة العر اقية كالثرطة و الجيش بل هددت بالقتل حتى الصحوات في الددينة

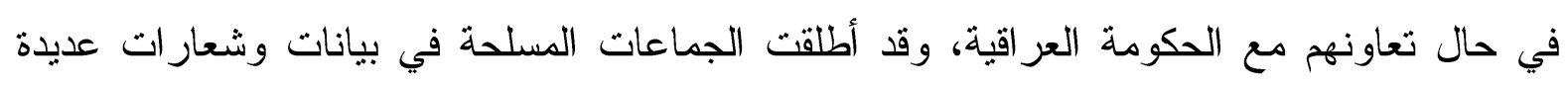
على أجهزة الأمن تسميات مشجعة للعنف في بيانات ضد تل الاجهزة فقد وصفت هذهِ الجماعات

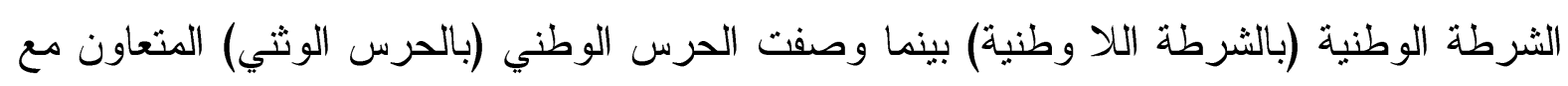
الاحتلال، ويبدو أن هذهِ الجماعات تريد أن تبقى هي من يمسك الأمن في البلاد في ظل التردي

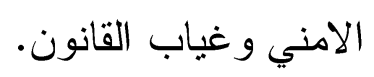
وفي إطار التهديدات لقوى الامن بترك أعمالهم و إلا فأن مصير هم سيكون القتل، وقد ترك كثير من أفراد الجيش والشرطة أعمالهم خوفاً على أرواحهم وقلة عددهم وعدتهم في مواجهة الارهاب 
و المسلحين، ويذكر أحد قادة الصحوات أن الجماعات المسلحة قد قتلت كثير من قادة الصحوات في إطار التهديدات المستمرة لأجهزة الامن. ثالثاً: الشعار ات الرمزية الداعية للعنف: كثيره هي الثعار ات التي استخدمتها جماعات العنف في العراق والشعارات و الرموز (symbol)، هي جزء من ثقافة المجتمع ولا بد أن يكون لتلك الشعار ات دلالات معينة لفكر معين أو معتقد يؤمن به الانسان وفقاً للتحليل الثقافي الانثروبولوجي. أما الشعار ات التي كانت تستخدمها بعض الجماعات في مدينة (الدورة) التي استطاعت دراستي أن توثقها عبر الملاحظة و المقابلة هع المبحوثين فهي كثيرة إذ أن أكثر الشعار ات كانت على شكل منشورات أو كتابات نكتب على جدران المنازل وشوارع المدينة و تلك الشعار ات جميعها ذات دلالات على العنف وأبرز تلك الشعار ات. 1 (و اقتلو هم حيث ثقفتموهم) r-ويل للشرطة اللاوطنية و الحرس الوثني. r- ويل للشيعة الرو افض و السنة المرتدين. ع- هذا بيت مطلوب للام، لا يباع و لا يؤجر. رابعاً : تهديم وتفجير المساجد والحسينيات والأضرحة والمزارات: لما تدهورت الاوضاع كثيراً في المنطقة، ظهر نوع جديد من الاعتداءات وهو الاعتداء على واتى واتئ المساجد والحسينيات. فلمساجد المسلمين على مر التاريخ دور فاعل في بناء الانسان من الناحية الروحية والاخلاقية من خلال حث المجتمع على القيم الاسلامية و المثل العليا التي ينبغي أن يكون عليها الإنسان فالدين في المجتمعات الإسلامية أداة فاعلة في عملية الضبط الاجتماعي الى جانب

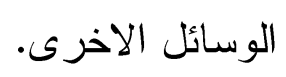
المساجد من وجهة نظري في وقتا الحالي سلاح ذو حدين فقد تكون وسيلة لتزويد المتلقي بثقافة التسامح و الوئام و الوحدة و المحبة بين مكونات المجتمع الواحد. أو لنشر التطرف والتعصب و العنف حيال الآخر. أما الجماعات المسلحة من خلال توجدها وسيطرثها على مناطق معينة في الدورة قامت بأعمال تخريب وتدمير لكثير من أماكن العبادة كالمساجد والحسينيات، وكثير من المناطق الساخنة قد شهت 
وهناك أكثر من أربعة مساجد وحسينيات هدمث غصبث بنايتها بسبب أعمال التوتز المذهبيالطائفي في المدينة.

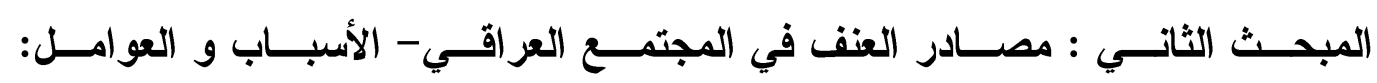
شهد العر اق بعد انهيار النظام السابق في ب . . ب أزمات متعددة وفي مقدمتها ظهور موجة و اسعة من اعمال العنف المستخدم بأشكال مختلفة (عمليات عنف مسلح - عمليات انتحارية - عمليات خطف الرهائن بأهداف مختلفة - عمليات التهجير القسري). لا شك أن كثيرا من العر اقيين يسألون ما الذي جعل العنف يندلع بهذِ الصورة المخيفة و البشعة ؟ مع أن ثقافة المجتمع العراقي ومكوناته فيها كثير من المشتركات الثقافية العامة وفي مقدمتها الدين و العادات و التقاليد وعلاقات الجيرة والمصاهرة، فضلاً عن الوئام المشترك الذي يدفع بإتجاه العيش المشترك بين المكونات و الطو ائف في مجتمع و احد بسوده الوئام و المحبة و التعاون. العنف المسلح المعاصر الذي ظهر في العراق الجديد لا يمكن ان يكون وليد الصدفة، وأنه من نتائج اسباب وعو امل مختلفة أدت الى ظهوره ولغرض الوصول الى عمق الظاهرة لا بد من معرفة أسبابه وعو امله التي تقف وراءه. وقد استطعت من خلال اجراء المقابلات الميدانية مع المبحوثين التوصل الى معرفة العديد من الأسباب والعوامل المسؤولة عن العنف المسلح وقد قسمت هذه

$$
\begin{aligned}
& \text { الأسباب الى خارجية وداخلية وهي الآتي : } \\
& \text { أولاً / الأسباب الخارجية : إن أهم هذه الأسباب: } \\
& \text { أ- الاحتلال الاجنبي : }
\end{aligned}
$$

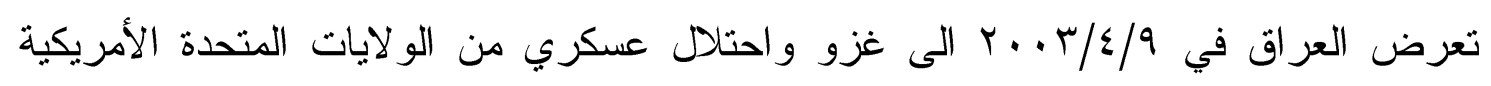
و القوات المتحالفة معها ، ما أدى الى خر اب ودمار واضح في البلد، مما أثز في المجتمع ، فكثير من المؤسسات انهار من دون أن تحرك القوات الامريكية ساكناً لإيقاف هذهِ التجاوزات والعمليات التخريبية - ـبل فتحت الابو اب أما المستغلين. وجود الاجنبي في أي وطن كان عندما يأتي مسمى (محرر) أو (محنل) سوف يثير عند ابن الوطن احساس الذل و الهوان و التحقير وهذا يدفع بالمو اطن الى ممارسة العنف ليس فقط ضد المحتل بل ضد من يستميلهم المحتل من الناس خشية ان يتفرد المتعاونون معه بالسلطة و المصالح، ومن هنا يحدثا التاريخ انه حيثما حكمت بغداد سلطة أجنبية ساد العنف أرجاء العراق. 
لقد أثار عدد من المبحوثين اثتاء المقابلة معهم الى أن قوات الاحتلال قد أدث الى إثارة مشاعر العنف من خلال قيامهم بما يأتي:

ا- القيام بالاعتقالات العشوائية لعدد كبير من المواطنين دون ذنب أو جريمة تذكر. r- عمليات القتل التي قامت بها قوات الإحتلال في مختلف مناطق العراق وتهديم بعض الدور و المنازل على أهلها فضلاً عن جرائم الاغتصاب التي حصلت في بعض السجون. ب- الفر اغ الأمني من خلال حل الجيش العر اقي و المؤسسات الأمنية الأخرى ومما سبب وجود عدد من العاطلين و البطالة، فضلاً عن السماح للناس بالاستيلاء على المتفجرات و الاسلحة من

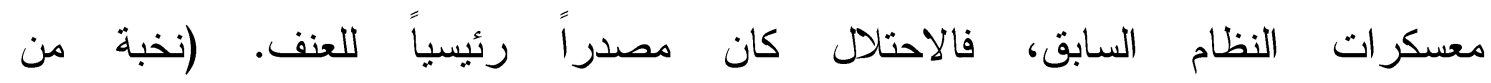

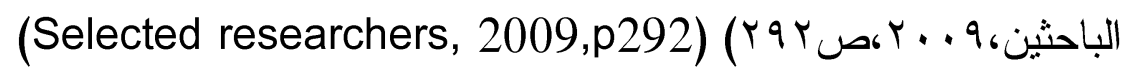

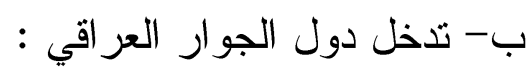
أدث الدول المجاورة للعراق دوراً واضحاً في شؤون العراق الداخلية فوظفت العديد من هذه الدول الطاقات الانتحارية و المادية والسياسية والافتائية في العراق والدليل على أن لهذٍِ الدول المجاورة دور افاعلا في القرار السياسي العراقي واستقرار الأمن العراقي هو تكرار الزيارات لكبار المسؤولين العر اقيين وقادة الكتل السياسية الى هذهِ الدول للتباحث في تشكيل الحكومة العراقية حتى بعد انتخابات عام • 1 •rم و ع ا •rم. فضلاً عن عائدية الاليات المستخدمة من التكفيريين التي كان بعضها مستوردا من دولها المنتجة تحت مسميات تعود لبعض دول الجوار، فضلاً عن كتب المخاطبات التي وجدت في أوكار بعض التكفيريين • أدى انفتاح الحدود دع دول الجوار الى تدفق كثير من المقاتلين العرب والاجانب الى العراق، وفي مقابلة أجريتها مع بعض المنتسبين العسكريين المسؤولين عن أمن المنطقة، أوضحوا انه قبض على العشرات من المقاتلين المتسللين عبر الحدود من جنسيات عربية واجنبية. و أدت امكانية العراق الاقتصادية وثرواته الكبيرة في بعض الاحيان الى تدخلهم في الثأن العر اقي، وتدخلهم هذا يكون بالقوى السياسية غير الرسمية في بلدانهم، وأصحاب الأعمال التجارية أو عن طريق المتمرسين في عالم الجريمة، فهناك دعم في الثبكات الاقليمية ومن الجماعات الاسلامية التي يتوجد فيها المتطوعون للأعمال الارهابية أو الانتحاريين ومهربي الاسلحة إذ تقوم هذه الشبكات 
بتزويدهم بالتدريب والخبرة في مجال الهجمات بالسيارات المفخخة، فهؤلاء المتطوعون يسهون في

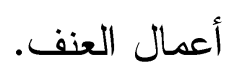

اما اسباب تدخل دول الجوار وتغذية العنف، فمن وجهة نظر المبحوثين هي للأسباب الاتية : 1- الخوف من التجربة الايمقراطية في العراق و النظام السياسي الجديد، فهناك تخوف من هذهِ التجربة التهابة التي ستطيح بالعديد من أنظمة هذِ البلدان. ץ- التهديدات الامريكية المتكررة لهذهِ البلدان، والخوف من إتخاذ العراق قاعدة امريكية لاحتلال العراق و الدول الاخرى، لذا فأصبح العراق ساحة تصفية النزاعات بين المتخاصمين.

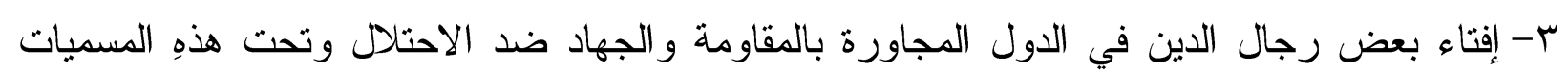
قتل الالاف من العر اقيين وفجرت المئات من المباني و المؤسسات.

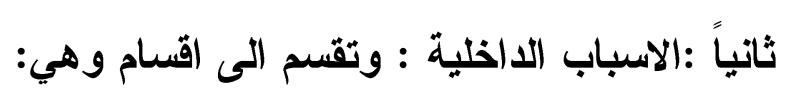
1- العوامل الاجتماعية: نقصد بها البيئة الاجتماعية والثقافة التي تحيط بالفرد (كالأسرة، العمل، الكاب،

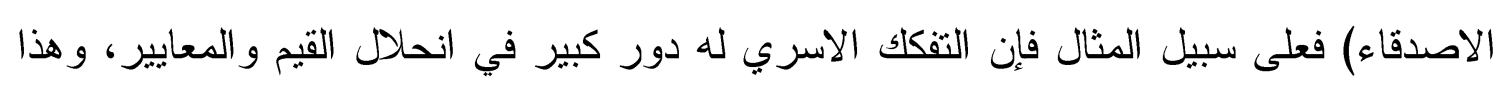

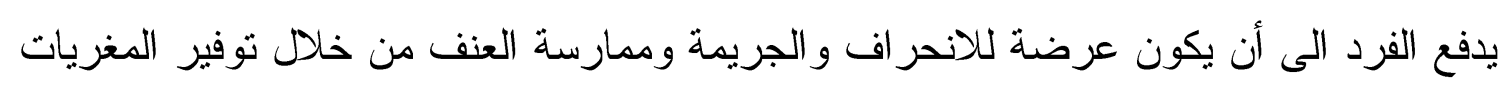

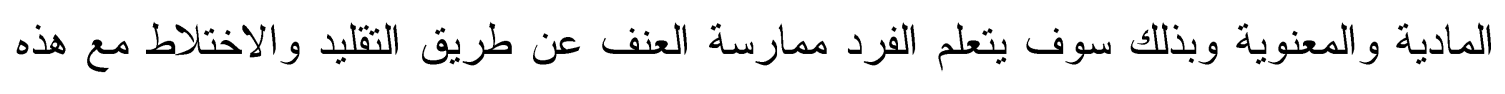
الجماعات. فكثير من الافر اد الذين لم يمارسوا العنف من قبل قد تدربو ا وتعلموا العنف على يد الديد جماعات العنف، تعلم كيفية القتل والاغتيال، وزرع العبوات الناسفة وتفخيخ السيار ات وتفجيرها.

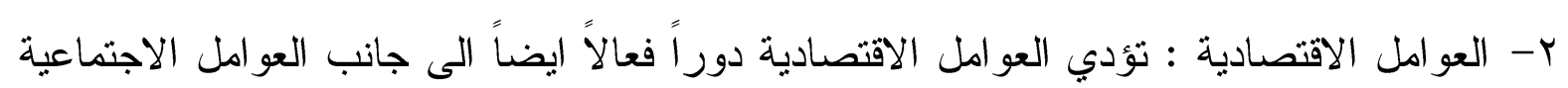

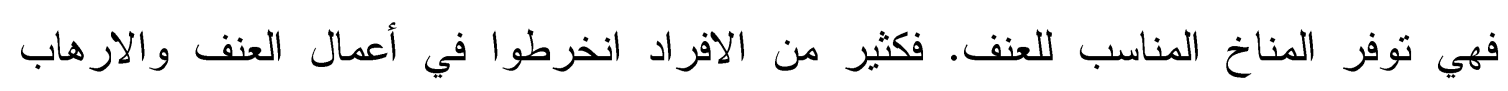

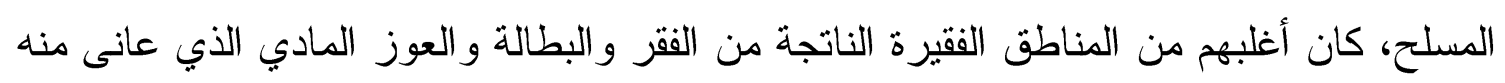

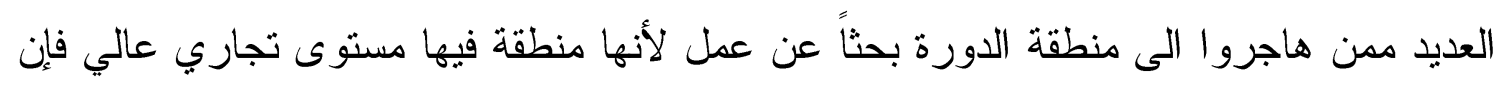

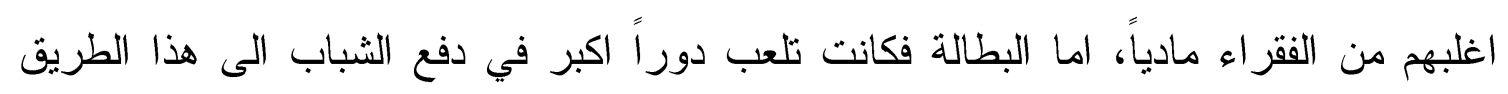

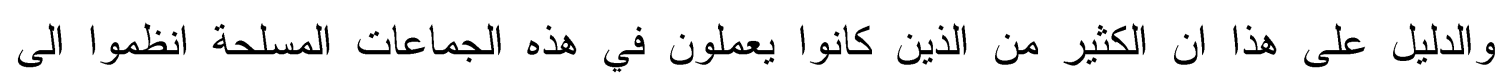

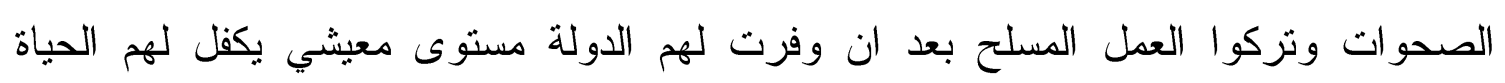

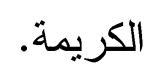


ب- عامل الجهل و الأمية: يعد الجهل والأمية ايضاً خصبة لكل أنواع التطرف والتعصب الديني أو السياسي فغالباً ما تستغل جماعات العنف والارهاب الجهلاء و الاميين من الناس لبث أفكارهم و غسل أدمغتهم بحجة الدين ومقولات الجهاد و المقاومة لإضفاء الشرعية على اعمالهم، ولتوظيف ذلك في أعمال طائفية أو سياسية ضد الآخرين بحجة (العمالة و الخيانة و التعاون مع المحتل) . اثبتث المعلومات أن غالبية جماعات العنف والارهاب هم ممن يعانون الجهل والامية وقلة الوعي فأغلبهر لا يمتلكون تحصيلا در اسيا يجعلهم يفكرون في نتيجة ما يفعلونه الأمر الذي جعلهم فريسة للمنطرفين و المتعصبين للعنف. الفصل الخامس : النتائـــج والتوصيـــــات والمقترحــات المبحث الاول / نتائســج الدراسة: بناءاً على ما تقدم توصلت الدر اسة الى عدة نتائج منها : ا-تبين أن العنف والازهاب المسلح في العراق بعد ب ...r أخذ عدة أشكال، فهناك القتل على الهوية و التهجير الطائفي، وعمليات اختطاف وسطو مسلح ، وتفجيرات انتحارية و اغتيالات سياسية، فالعنف كان له صور عديدة و اهداف مختلفة.

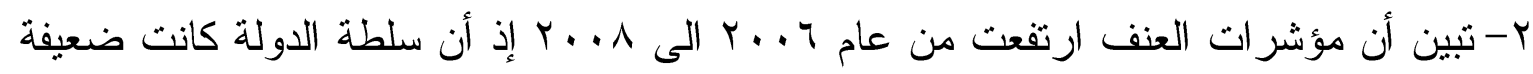
كلما رجعنا بهذهِ السنوات والفراغ الأمني الذي شهده البلد، شهد على ظهور الجماعات الارهابية والميليشيات، وما بعد عام ^ ... فإن وتيرة العنف انخفضت وقامت عدة عمليات عسكرية ضد هذهِ الجماعات وبرز ما يُسمى المصالحة الوطنية و الصحو ات التابعة للدولة. ب-تبين أن العنف بسبب الارهاب كان أقل نسبياً من الضحايا من الأمريكان أو قوات الاحتلال و هذا يعني أن المستهدف بالعنف كان المجتمع العراقي ، أما الجهاد و المقاومة فقد عملت بشكل صحيح لكن بنسبة قليلة مقارنة بأعمال العنف. ع- العنف والارهاب قد سببّ هجرة الالاف من العر اقيين داخل العراق وخارجه حفظاً لحياتهم

$$
\text { ه- العنف الذي حصل في الفرة كثير من الكفاءات (أساتذة جامعات - أطباء - قضاة - مهندسين.... الخ). }
$$




$$
\text { ب. ب. الاحتلال الاجنبي للعر اق }
$$

ت. تبين أن العنف ليس له شكل واحد، فالعنف استهدف كثير ا من الطوائف والأثثات من :(المدنيين و العسكريين، الرجال و النساء و الاطفال) واستهدف العنف الاماكن جميعها من (الاسو اق و البنايات و الجسور) و الجو امع و الحسينيات و الاضرحة والمزارات و الوزارات و الجامعات... الخ) فلم ينبق مكان في بلدنا لم يستهدفه العنف. تبين ان العنف الذي حصل في العراق هو (عنف طائفي) بالدرجة الاولى قبل ان يكون (عنف سياسي) بالمرتبة الثانية. تبين أن أغلب أعمال العنف كانت ناتجة عن دعم خارجي اقليمي لا سيما دول الجوار وكان هذا

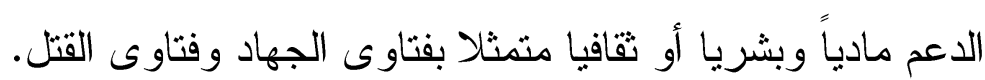
المبحــــث الثاني / التوصيــات والمقترحات أولاًا : التوصيـات : ا-ضرورة نبذ العنف بكل أنواعه ابتداءاً من العنف الأسري وصو لاً الى العنف المسلح وتفعيل دور التفاهم بدلاً من ممارسة العنف في حل المشكلات. r- الدعوة الى التسامح مع الآخر من خلال المؤسسات التربوية والاعلامية لما لها من دور ايجابي

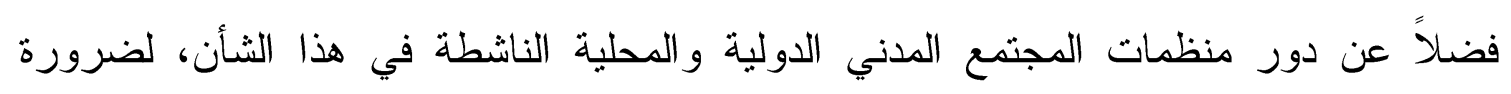
العيش المشترك بين جميع الأطياف و المذاهب و القوميات. ب-رفع المستوى الثقافي و التعليمي لأفراد المجتمع، و القضاء على الجهل والامية و التخلف لأنه من ولن العو امل الدافعة لأعمال العنف. ريع. ع - تعميق روح الانتماء الى الوطن من أجل نبذ الطائفية والعشائرية. 


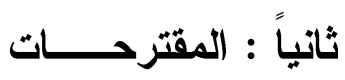

ا- اجراء دراسات ميدانية متعددة عن العنف والإزهاب في مناطق اخرى ساخنة بالعنف و الار هاب و اجر اء مقارنات بين هذهِ الدر اسات.

$$
\text { r- ضرورة تجريم وتحريم فتاوى الدعوة الى الإزهاب و العنف و القتل و التكفير • }
$$

r- تفعيل دور المؤسسات التربوية لوضع مناهج تتبذ العنف وتدعو الى التسامح بين كل أطياف

$$
\text { المجتمع العر اقي، ابتداءاً من المدرسة الى الجامعة. }
$$

ع- الحد من استير اد اللعب الخاصة بالأطفال التي تشجع على تتمية العنف في نفوس الاطفال الى

$$
\text { غير ذلك من المسلسلات و الافلام التي تتمي ثقافة العنف و الارهاب. }
$$

ه- دمج الوققين (السني) و (الشيعي) بوقف واحد للحد دن ظاهرة العنف والارهاب بين مكونات

$$
\text { المجتمع العر اقي مع مر اعاة خصوصية كل مذهب من المذاهب. }
$$

\section{References}

-Ibn Mnadour,(1988), The tongue of the Arabs, Dar Arabs Tongue, Beirut, volume (1-4).

- Abu Zaid, Ahmed, (1978), Lectures in Cultural Anthropology, Dar alNahda al-Arabiya, Beirut.

- Zahlawi, Elias,(1980) Society and Violence, University Institution for Studies and Publishing, Beirut.

- Al-Fatlawi, Suhail,(2002), Terrorism and International Terrorism, Cultural Affairs office 1st ed, Baghdad.

- Attieah, Ahmed, (1968), Political Dictionary, Dar al-Nahda Arab, Cairo, I 3.

- Bin Khaldun, Abdul Rahman, (without a year printed), 3rd ed, Introduction, the investigation of Ali Abdul Wahid Wafi, Dar alNahda, Cairo.

- Salloum, Saad,(2008), Scapegoat of redemption, Journal of Pathways, p. 3 , special issue on the war, Baghdad.

- Jamel, Dr. Asmaa,(2007), Social Violence, House of Cultural Affairs, Baghdad, $1^{\text {st }}$ ed.

- Al-Saleh, Qassem Hussein,(2008), The theory of Al Wardi is no longer valid, International Information Network (Internet), at http://www.radiodijla.com 
- Hafez, Dr.Nahida Abdel-Karim, (1981), Introduction to the design of social research, Al-Ma'aref Press, Baghdad.

- Al-Bayati, Dr.Alaa,(2008),Anthropological Research Methods, Lectures on higher Students (Masters).

- Selected researchers,(2009), Ali Al-Wardi and the Iraqi project, the Egyptian Foundation for Iraqi Book, Baghdad.

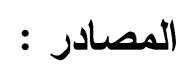

- - ابن منظور، (9^^ (م)، لسان العرب، دار لسان العرب، بيروت، مجلد (1-ع). - - أبو زيد، د.احمد، (9 (م)، محاضرات في الانثروبولوجيا الثقافية، دار النهضة العربية، بيروت.

- - عبه ، أحمد، (971 (م)، القاموس السياسي، دار النهضة العربية، القاهرة، طس.

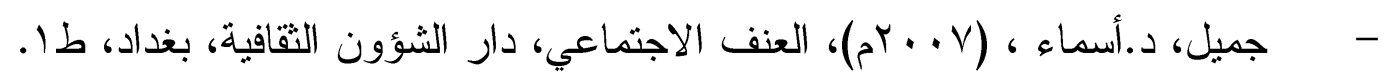

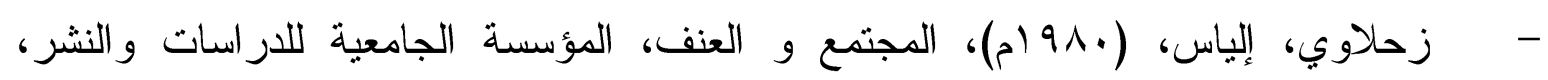
بيروت

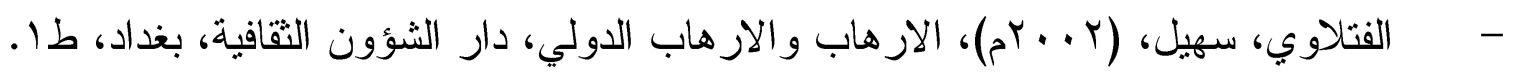

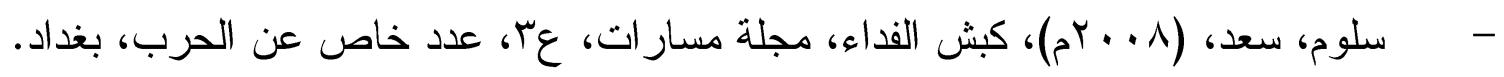
- - بن خلدون، عبد الرحمن، (بدون سنة طبع)، المقدة، تحقيق علي عبد الواحد وافي، دار النهضة، القاهرة، جب، طب.

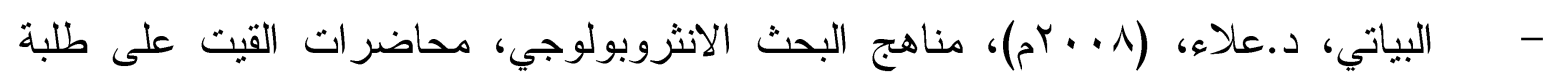
الدر اسات العليا (الماجستير).

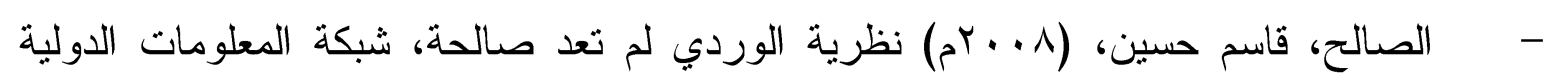
http://www.radiodijla.com (الانتزنت)،على الموقع الالكتروني: - حافظ ، د.ناهدة عبد الكريم، (1919)، مقدمة في تصميم البحوث الاجتماعية، مطبعة المعارف، بغداد. - - نخبة من الباحثين، (9 . . rم)، علي الوردي و المشروع العراقي، مؤسسة مصر للكتاب العر اقي، بغداد. 